\title{
Avaliação de Dois Métodos in vitro para Determinar a Cinética Ruminal e a Digestibilidade Intestinal da Proteína de Vários Alimentos ${ }^{1}$
}

\author{
Fernando Iván Londoño Hernández ${ }^{2}$, Sebastião de Campos Valadares Filho ${ }^{3}$, \\ Rogério de Paula Lana ${ }^{3}$, Antonio Bento Mancio ${ }^{3}$, Mario Fonseca Paulino ${ }^{3}$, Paulo Roberto \\ Cecon $^{4}$, Rilene Ferreira Diniz Valadares ${ }^{4}$, Karla Alves Magalhães ${ }^{5}$, Sandro Luiz Rosa Reis ${ }^{5}$
}

\begin{abstract}
RESUMO - Este trabalho foi realizado com o objetivo de avaliar a degradabilidade ruminal e a digestibilidade intestinal dos compostos nitrogenados de 18 alimentos concentrados e quatro alimentos volumosos, utilizando o método de inibidores com digestão intestinal em HCL-pepsina-pancreatina e o método de três estádios. No método dos inibidores, cada alimento foi incubado, nos tempos 0 e 2 horas, na quantidade de $1,875 \mathrm{mg}$ de N, utilizando-se três tubos de incubação, sendo um deles deixado para avaliação da digestão intestinal. No segundo método, aproximadamente $5 \mathrm{~g}$ da amostra de cada alimento foram incubados durante 16 horas no rúmen de bovino recebendo dieta com $60 \%$ de volumoso e $40 \%$ de concentrado. Uma quantidade de $15 \mathrm{mg}$ de $\mathrm{N}$ residual do rúmen de cada alimento foi colocada em tubos de digestão (frascos de $50 \mathrm{~mL}$ ) para serem incubados em HCL-pepsina-pancreatina durante 25 horas. A digestibilidade intestinal da proteína não-degradada no rúmen dos alimentos avaliados não foi constante. O método dos inibidores estimou melhor a degradação ruminal da proteína bruta e o método de três estádios, a digestibilidade intestinal da proteína não-degradada no rúmen.
\end{abstract}

Palavras-chave: degradabilidade, digestibilidade intestinal, proteína não-degradada no rúmen

\section{Application of Two in Vitro Methods for Evaluation of Ruminal Disappearance and Intestinal Digestibility of Feed Protein}

\begin{abstract}
The objective of this work was to evaluate the ruminal disappearance and nitrogen intestinal digestibility of 18 concentrate feedstuffs and four grasses, using an in vitro inhibitor with HCL-pepsin-pancreatin solutions and the three-step method. The disappearance of nitrogen compounds of feedstuffs was determined at 0 and 2 hours using $1.875 \mathrm{mg}$ of $\mathrm{N}$ incubated on each three vessels. One of the vessels was submitted to intestinal digestion. On the second method, approximately $5 \mathrm{~g}$ of samples were incubated, during 16 hours, in the rumen of a steer fed a diet with 60:40 forage to concentrate ratio. After the incubation period, samples containing $15 \mathrm{mg}$ of residual $\mathrm{N}$ were incubated in HCL-pepsin-pancreatin solutions during 25 hours. Data of intestinal digestibility of ruminal undegradable protein was not constant. The inhibitor method was more efficient to evaluate and predict kinetic parameters of ruminal degradation and the three-step method for intestinal digestibility of ruminal undegradable protein.
\end{abstract}

Key Words: degradability, intestinal digestibility, ruminal undegradable protein

\section{Introdução}

O inadequado suprimento de nutrientes na dieta dos animais é responsável pelo baixo desempenho, sendo que a proteína é, sem dúvida, um dos nutrientes de maior custo na ração. As exigências de proteína dos ruminantes são atendidas pela proteína microbiana sintetizada no rúmen, pela proteína dietética que escapa à degradação ruminal e pela proteína endógena reciclada. As taxas de degradação são responsáveis pelo maior ou menor escape de compostos nitrogenados $(\mathrm{N})$ do rúmen e pelo atendimento dos requerimentos de compostos nitrogenados dos mi- crorganismos ruminais. Conseqüentemente, a determinação da degradabilidade ruminal da proteína, sem o conhecimento da digestibilidade intestinal da fração que escapa à degradação ruminal, parece não ser adequada (Valadares Filho, 1995).

No que diz respeito à digestibilidade intestinal da proteína, ainda considera-se que esta seja constante. O ARC (1984) e o NRC $(1985,1989)$ adotaram, respectivamente, o valor de 85 e $80 \%$, para a digestibilidade intestinal da proteína não-degradada no rúmen. No AFRC (1992), foi assumido o valor de $90 \%$ para a digestibilidade da proteína no intestino delgado, que pode ser obtida pela seguinte

\footnotetext{
${ }^{1}$ Parte da tese de Doutorado do primeiro autor, parcialmente financiada pela FAPEMIG.

2 Aluno de Doutorado do DZO - UFV. E.mail: flondono@alunos.ufv.br

3 Professor do DZO - UFV 36571-000 Viçosa, MG. E.mail: scvfilho@mail.ufv.br

${ }^{4}$ Professor do DPI - UFV 36571-000 Viçosa, MG.

${ }^{5}$ Aluno de graduação UFV.
} 
expressão: DPNDR (digestibilidade da proteína nãodegradada no rúmen $)=0,9$ [(PNDR) - 6,25 NIDA]. No CNCPS, foram considerados diferentes valores para as três frações protéicas potencialmente digeríveis: $100 \%$ para as frações $B_{1}$ e $B_{2}$ e $80 \%$ para a fração $B_{3}$ (Sniffen et al., 1992).

Uma maneira de se avaliar a digestibilidade pósruminal da proteína não-degradada no rúmen seria por intermédio da técnica de sacos de náilon móveis. Entretanto, os estudos utilizando animais canulados são laboriosos, caros e requerem tratamento especial. Por outro lado, Calsamiglia \& Stern (1995) desenvolveram a técnica in vitro de três estádios para estimar a digestibilidade intestinal da proteína de vários alimentos. A técnica assume que a contaminação microbiana é mínima e mostrou-se sensível ao avaliar o efeito do processamento e a presença do fator inibidor da tripsina dos alimentos e teve alta correlação com estudos in vivo. O NRC (2001) recomenda utilizar as técnicas do saco de náilon móvel e de três estádios para estimar a digestibilidade intestinal da PNDR. A técnica dos inibidores in vitro (IIV) de Broderick (1987) ainda não foi testada para estimar a digestibilidade intestinal da PNDR.

Os objetivos desta pesquisa foram determinar a degradabilidade ruminal e a digestibilidade intestinal da proteína de vários alimentos, utilizando duas técnicas in vitro: a de três estádios e a dos inibidores in vitro (IIV).

\section{Material e Métodos}

Este trabalho foi realizado nas dependências do laboratório de Nutrição Animal, do Departamento de Zootecnia, da Universidade Federal de Viçosa. Foram avaliados dois métodos in vitro. No primeiro, a dinâmica da degradação ruminal dos compostos nitrogenados dos alimentos foi avaliada pela incubação in vitro com o uso de inibidores (IIV) (Broderick, 1987, modificado por Londoño Hernández et al., 2000).

Foi utilizado, como inóculo, líquido ruminal oriundo de bovino recebendo dieta com $60 \%$ de volumoso (capim-elefante) e $40 \%$ de concentrado (farelo de soja $60 \%$, fubá de milho $20 \%$, farelo de trigo $15 \%$, farinha de sangue $2 \%$, fosfato bicálcico $1 \%$, calcário $1 \%$ e sal mineral $1 \%$ ).

Foi utilizado o método Kjeldahl (AOAC, 1990) para determinar o teor dos compostos nitrogenados (N) dos seguintes alimentos: caseína, farelo de soja, farelo de trigo, fubá de milho, milho desintegrado com palha e sabugo (MDPS), glúten de milho, grão de sorgo moído, grão de milheto moído, grão de amendoim moído, polpa cítrica, farelo de glúten de milho. Foram também avaliadas as farinhas de peixe, de penas, de vísceras de aves e mista de vísceras de aves e suínos, além das camas de frango contendo como material absorvente capim-elefante, casca de café e cepilha de madeira. Foram ainda avaliados os volumosos: silagem de milho (Zea mays), capimbraquiária (Brachiaria decumbens cv. Basiliski) $\left(2^{\circ}\right.$ ano) coletado no início das águas com idade de 45 dias, os fenos de capim-Tifton (Cynodon dactylon) com 5 semanas de idade e a silagem pré-seca de Tifton.

As amostras de cada alimento foram processadas em moinho de bola e incubadas em três dias diferentes. Cada alimento foi incubado nos tempos 0 e 2 horas, na quantidade de $1,875 \mathrm{mg}$ de $\mathrm{N}$ para cada três tubos de incubação, sendo que um dos tubos de cada amostra foi deixado para avaliação da digestão intestinal, de acordo com Calsamiglia \& Stern (1995).

Inicialmente, a cada tubo de digestão de $50 \mathrm{~mL}$ foram adicionados $10 \mathrm{~mL}$ de uma solução $0,1 \mathrm{~N}$ de HCL contendo $1 \mathrm{~g} / \mathrm{L}$ de pepsina com $\mathrm{pH}$ de 1,9 , sendo incubado em banho-maria a $38^{\circ} \mathrm{C}$ durante $1 \mathrm{~h}$. Posteriormente, foram adicionados $0,5 \mathrm{~mL}$ de uma solução de $\mathrm{NaOH} 1 \mathrm{~N}$ e 13,5 mL de uma solução de pancreatina (0,5M de fosfato de potássio dibásico $\mathrm{KH}_{2} \mathrm{PO}_{4}$ com $\mathrm{pH}$ de 7,8 contendo $50 \mathrm{ppm}$ de thymol e $3 \mathrm{~g} / \mathrm{L}$ de pancreatina), colocando o tubo, novamente, em banho-maria a $38^{\circ} \mathrm{C}$ durante $24 \mathrm{~h}$, sendo agitado lentamente a cada 8 horas.

Ao finalizar a digestão, foram adicionados $3 \mathrm{~mL}$ de ácido tricloroacético (TCA-100\%) em cada tubo para encerrar a ação enzimática e precipitar as proteínas não- digeridas. Cada tubo foi deixado em repouso durante 15 minutos e, posteriormente, centrifugado a $10.000 \mathrm{x}$ g durante 15 minutos a $4{ }^{\circ} \mathrm{C}$, sendo o sobrenadante analisado para $\mathrm{N}$.

No segundo método, a degradação ruminal e a digestibilidade intestinal foram avaliadas pelo método de três estádios, de acordo com Calsamiglia \& Stern (1995). As amostras foram moídas em moinho provido de peneira com malha de $2 \mathrm{~mm}$. Aproximadamente $5 \mathrm{~g}$ da amostra de cada alimento foram colocados nos sacos de poliéster, tamanho $10 \times 6 \mathrm{~cm}$ e incubados no rúmen por 16 horas. A seguir, os sacos foram lavados em água corrente, sem esfregar, até a mesma sair limpa, levados à estufa de ventilação forçada durante 48 horas a $55^{\circ} \mathrm{C}$, pesados e determinados os teores de nitrogênio. Uma 
quantidade de amostra contendo aproximadamente $15 \mathrm{mg}$ de nitrogênio residual do rúmen de cada alimento foi colocada em tubos de digestão para a realização da digestão intestinal, como descrito anteriormente.

Foram realizadas determinações de matéria seca (MS), matéria orgânica (MO), matéria mineral (MM) e extrato etéreo (EE), seguindo os procedimentos descritos pelo (AOAC, 1990), além dos carboidratos totais (CHT) estimados pela equação (Sniffen et al., 1992): CHT (MS) = 100$(\% \mathrm{~PB}+\% \mathrm{EE}+\% \mathrm{MM})$ e dos compostos nitrogenados não-protéicos (NNP) determinados de acordo com Licitra et al. (1996). A composição bromatológica dos alimentos avaliados encontra-se nas Tabelas 1 e 2 .

Os cálculos da degradação ruminal e digestibilidade intestinal pelo método de três estádios foram realizados de acordo com as seguintes equações: a degradabilidade ruminal foi calculada, $\mathrm{PDR}=100 \times\{[$ (nitrogênio incubado - nitrogênio residual)/ nitrogênio incubado]\}. A digestibilidade intestinal, em porcentagem, foi calculada como a quantidade de $\mathrm{N}$ digerido após incubação com HCLPepsina e pancreatina dividida pela quantidade incubada e multiplicada por 100 e a proteína nãodegradada no rúmen, como: PNDR = 100 - PDR.

Os cálculos da degradação ruminal e digestibilidade intestinal pelo método de inibidores foram realizados de acordo com as seguintes equações:

Taxa de degradação, Kd $(/ \mathrm{h})=-\left(\operatorname{LnFID}_{2 \mathrm{~h}}-\right.$

$$
\left.\operatorname{LnFID}_{\text {oh }}\right) / 2 \text {; }
$$

em que: $\operatorname{LnFID}_{\mathrm{oh}}=\left\{1-\left[\left(\left(\right.\right.\right.\right.$ Ninsolúvel $\left.\mathrm{TCA}_{\mathrm{oh}}\right) /$ Nincubado $)]\} ; \operatorname{LnFID}_{2 \mathrm{~h}}=\left\{1-\left[\left(\left(\right.\right.\right.\right.$ Ninsolúvel $\left.\mathrm{TCA}_{2 \mathrm{~h}}\right) /$ Nincubado)] \}, em que: Ninsolúvel em TCA, para 0 e $2 \mathrm{~h}=\operatorname{mg}$ (Ninsolúvel TCA - Nbranco); Fração B, B $(\%)=\left[\operatorname{Exp}\left(\operatorname{LnFID}_{\mathrm{oh}}\right) \times 100\right]$ e a proteína de escape calculada como: PNDR $(\%)=[\mathrm{Kp} /(\mathrm{Kd}+\mathrm{Kp})]$, assumindo-se taxa de passagem de $0,05 / \mathrm{h}$.

A degradabilidade ruminal foi calculada como: PDR $=100-$ PNDR e a digestibilidade intestinal, como: DIPNDR $=\{[($ Ninicial $x$ PNDR $)$ - Ninsolúvel em TCA após rúmen e intestino]/ (Ninicial $x$ PNDR $\} \times 100$.

As estimativas médias das digestibilidades intestinais da proteína não-degradada no rúmen, utilizando o método de inibidores e o método de três estádios, foram comparadas por intermédio do teste "t", a 5\% de probabilidade.

\section{Resultados e Discussão}

Os valores médios estimados da proteína degradada (PDR), não-degradada no rúmen (PNDR) e a digestibilidade intestinal da proteína não-degradada no rúmen (DIPNDR) dos alimentos concentrados avaliados pela técnica de três estádios são apresentados na Tabela 3. As pressuposições feitas nas avaliações realizadas foram que a proteína que escapa à degradação ruminal e sua digestibilidade no intestino não são constantes, o que foi comprovado pelos resultados obtidos, sendo que a proteína não-degradada no rúmen dos alimentos concentrados avaliados variou de 6,85 a $84,26 \%$ para caseína e farinha de peixe, respectivamente. Já a digestibilidade intestinal alcançou valores que variaram de 32,22 a 93,33\% para a polpa cítrica e a caseína, respectivamente.

Este estudo confirmou os resultados de De Boer et al. (1987), Van Straalen \& Tamminga (1990), Kendall et al. (1991), Castillo (1992), Hvelplund et al. (1992), Ramos et al. (1995), Valadares Filho (1995) e Londoño Hernández et al. (1998), em que a digestibilidade intestinal da PNDR não foi constante.

Como pode ser observado, a caseína avaliada por intermédio do método de três estádios teve alta degradação ruminal e a proteína que escapou à degradação ruminal foi baixa $(6,85 \%)$. Entretanto, esse resultado foi $63,95 \%$ menor que o preconizado pelo NRC (1989) de $19,00 \%$. Por outro lado, a digestibilidade intestinal da proteína não-degradada no rúmen foi elevada, indicando que, provavelmente, essa fração seria amplamente digerida. Na literatura, não foram encontrados dados sobre a digestibilidade intestinal da proteína que escapa à degradação ruminal da caseína.

O farelo de soja tem sido utilizado como suplemento protéico de alta qualidade, sendo degradado no rúmen em maior extensão que proteínas de origem animal. Os resultados mostraram que metade da proteína desse alimento foi degradada após 16 horas de incubação no rúmen. Entretanto, foi encontrada grande variação nos resultados da proteína degradada no rúmen: De Boer et al. (1987), 86,10\%; Masoero et al. (1994), 80,24\%; Stern et al. (1997), 80,6\%; Londoño Hernández et al. (1998) 72,36\%, utilizando a técnica do saco de náilon móvel.

Com base em estudos in vivo, o NRC (1985) considerou em $72,00 \%$ a degradação ruminal do farelo de soja. Com relação à proteína não-degradada no rúmen (PNDR), o farelo de soja apresentou valor de 49,22\%. Entretanto, Stern et al. (1983) relataram 


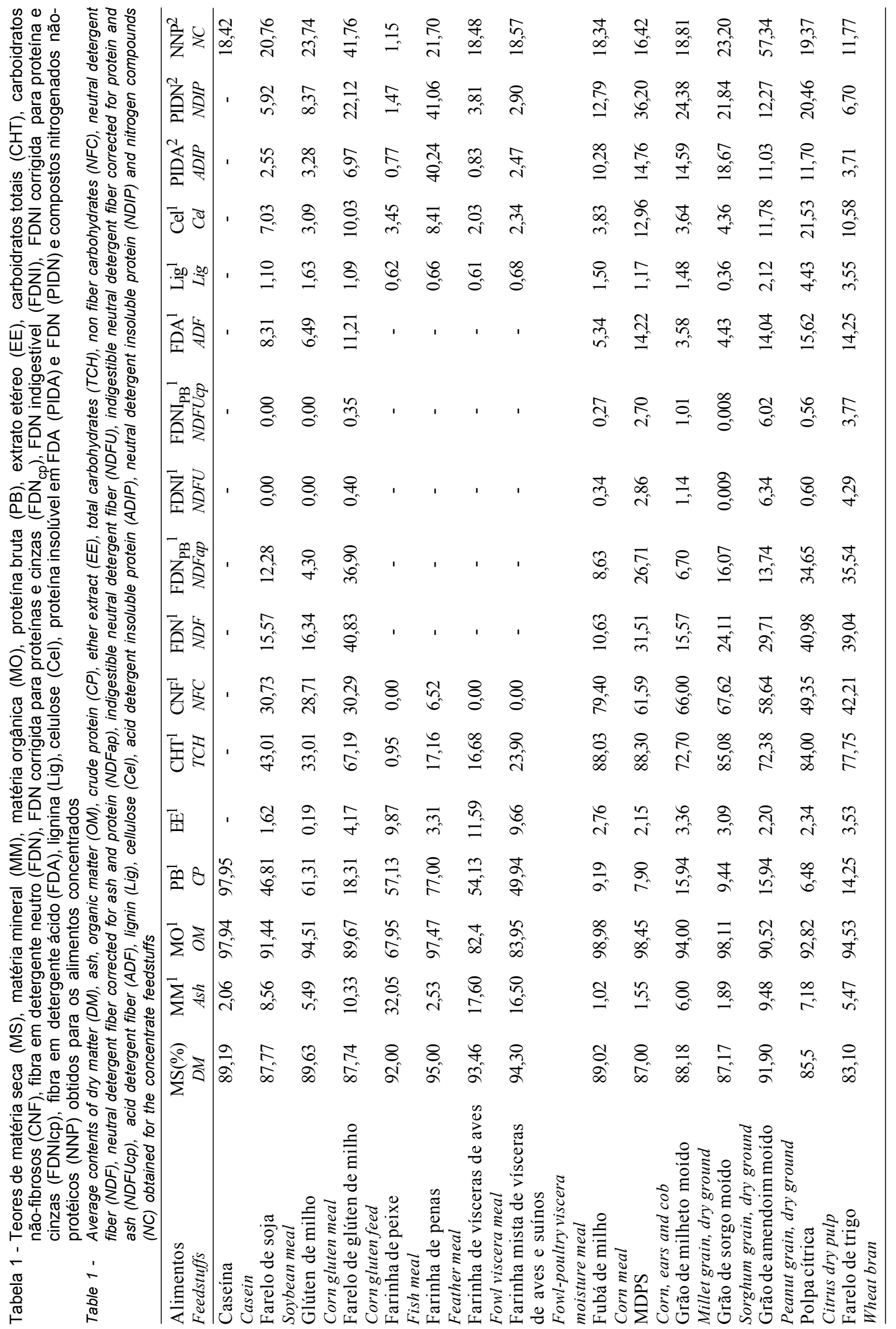




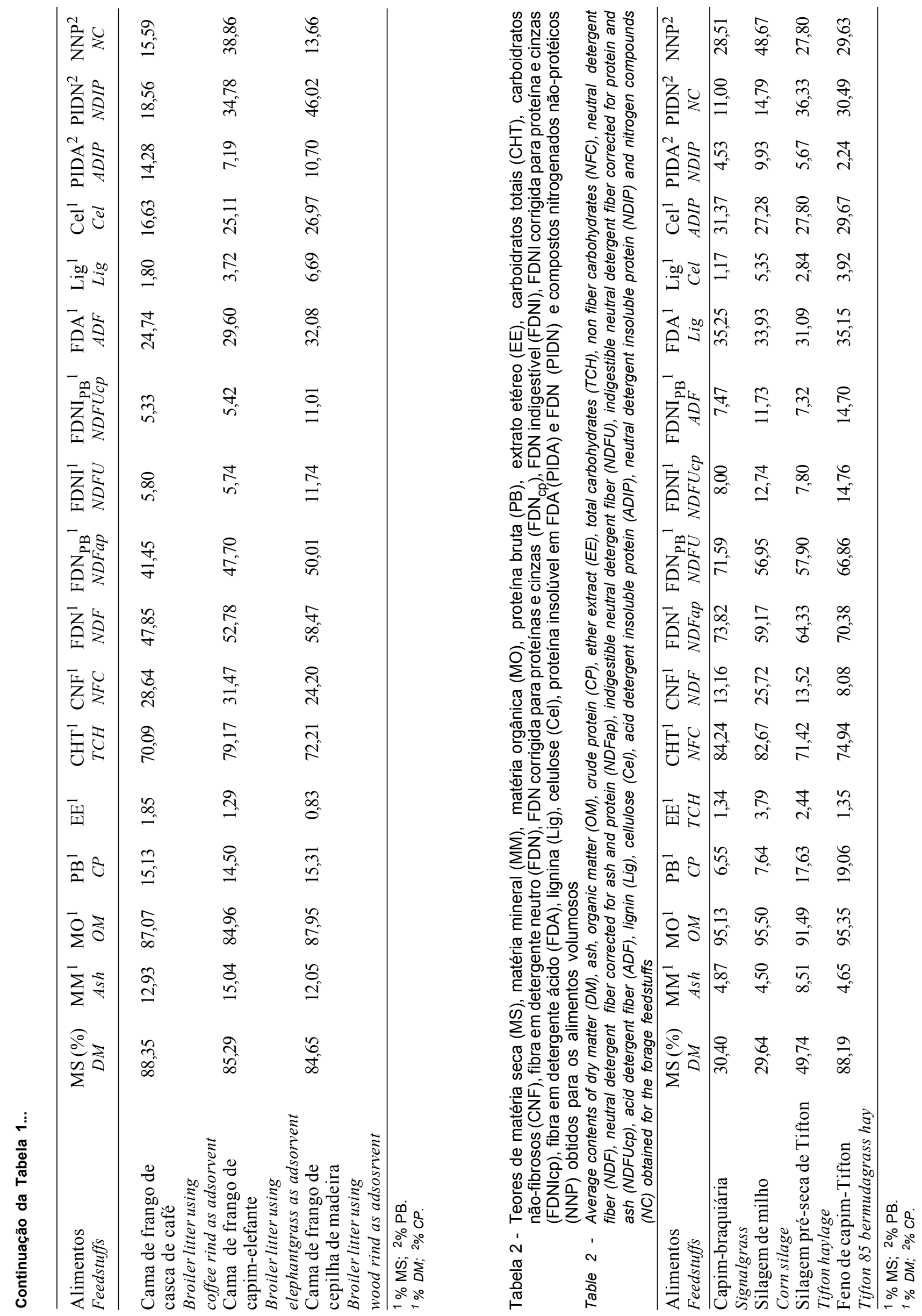


variações para a PNDR de 22,00 a 29,00\% e Merchen et al. (1997), de 35,00 a 93,00\%. Por outro lado, o NRC (1989) considerou valores de 14,00 a $82,00 \%$ para a PNDR do farelo de soja, dependendo do tipo de tratamento. A digestibilidade intestinal foi de 84,67\%, semelhante à encontrada por Maiga et al. (1996), 88,00\%; Cabral(1999), 82,68\%; e Calsamiglia \& Stern (1995), 89,80\%, utilizando a técnica de três estádios.

O glúten de milho teve a segunda maior fração da proteína não-degradada no rúmen, com valor de $81,62 \%$, e sua digestibilidade intestinal foi semelhante à do farelo de soja, com valor de $84,00 \%$. Os resultados obtidos no presente trabalho foram semelhantes aos encontrados por Maiga et al. (1996), 13,90; 86,10; e 84,0\% e Cabral (1999), 18,00; 82,00; e 83,25\% para a PDR, PNDR e digestibilidade intestinal da PNDR, respectivamente. A digestibilidade intestinal também foi semelhante à obtida por Calsamiglia \& Stern (1995), de 87,60\%. Clark et al. (1987) e Poos-Floyd et al. (1985) relataram valores de 55,00 e $57,90 \%$ para o teor da PNDR; já o NRC (1989) publicou valores para a PNDR do glúten de milho de 22,00 a $55,00 \%$, dependendo do tipo de processamento. Avaliando o glúten de milho, em um estudo in vivo, Titgemeyer et al. (1989) encontraram digestibilidade intestinal de $69,00 \%$, resultado aproximadamente $17,86 \%$ menor que o encontrado nesta pesquisa.

No que diz respeito aos alimentos de origem animal, observou-se que a menor degradação ruminal foi obtida pela farinha de peixe $(15,74 \%)$, seguida pela farinha de penas $(25,60 \%)$, farinha de vísceras de aves $(47,44 \%)$ e, por último, pela farinha mista de vísceras de aves e suínos $(48,60 \%)$. Os resultados da degradabilidade ruminal (15,74\%), PNDR $(84,26 \%)$ e digestibilidade intestinal $(79,76 \%)$ da farinha de peixe foram próximos aos encontrados por Cabral (1999): 11,07; 88,93; e 73,37\%, respectivamente. Calsamiglia e Stern (1995) encontraram digestibilidade intestinal de $85,40 \%$, sendo esse resultado $6,60 \%$ maior que o encontrado neste estudo. Entretanto, em um estudo in vivo, Zerbini \& Polan (1985) encontraram degradabilidade ruminal da farinha de peixe de $42,70 \%$. Também in vivo, McCarthy et al. (1989) relataram digestibilidade intestinal de $72,30 \%$ para esse mesmo alimento. Já o NRC (1989) considerou o valor de $60 \%$ para a PNDR da farinha de peixe.

Com relação ao fubá de milho, as estimativas médias mostraram que esse alimento foi $42,21 \%(31,81 \%)$ mais degradado no rúmen que o glúten de milho (18,38\%), sendo, portanto, a proteína de escape $16,50 \%$ menor
Tabela 3 - Estimativas do percentual da proteína degradada no rúmen (PDR), que escapa à degradação ruminal (PNDR) e digestibilidade intestinal da proteína (DIPNDR) obtidas para alimentos concentrados e camas de frango, utilizando o método de três estádios

Table 3 - Estimates of ruminal degradable protein (RDP), ruminal escape (NDRP), and intestinal digestibility of ruminal escape (IDNDRP) obtained for concentrate and broiler litter feedstuffs by the three-step method

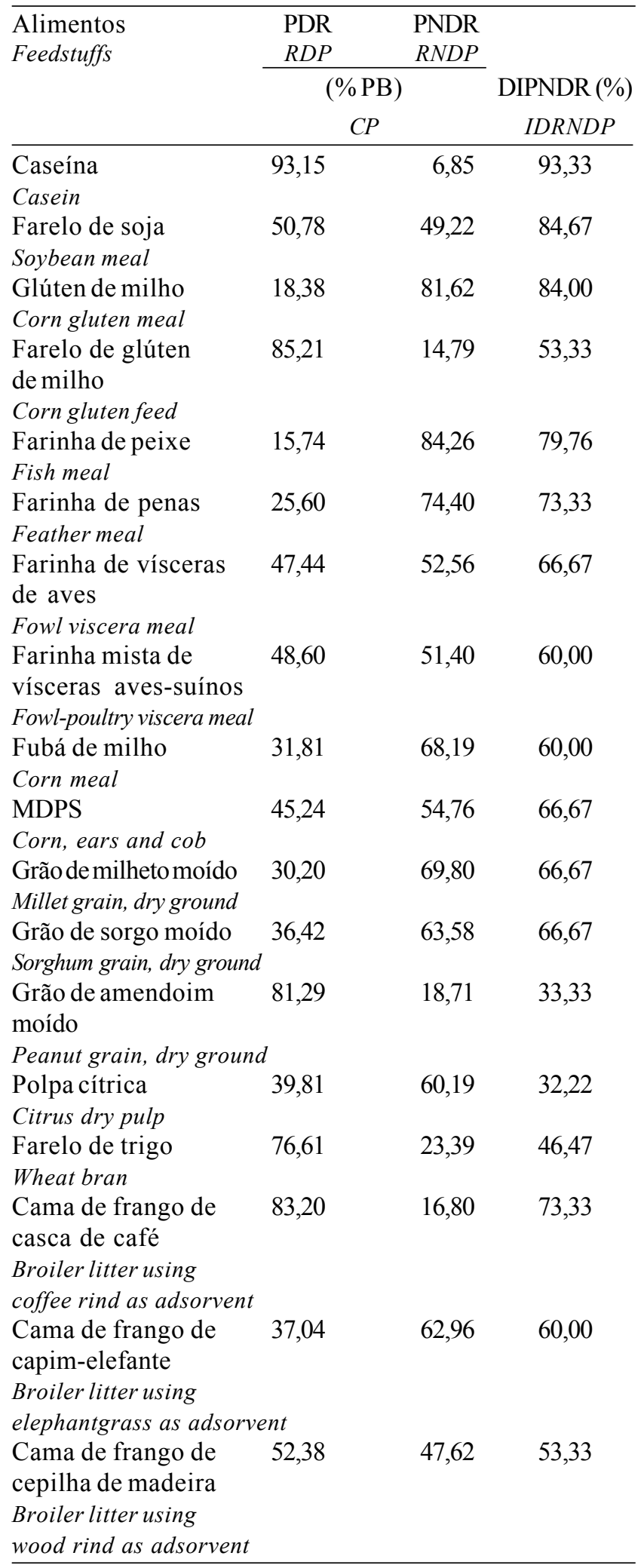


$(68,19 \%)$ que a do glúten $(81,62 \%)$ e a digestibilidade intestinal da PNDR, 28,57\% menor, 60,00 e 84,00\%, respectivamente. Os resultados obtidos foram próximos aos encontrados por Cabral (1999), de 30,00, 70,00 e $56,19 \%$ para a PDR, PNDR e digestibilidade intestinal da PNDR, respectivamente. Resultados semelhantes aos encontrados no presente trabalho foram relatados em um estudo in vivo por Kung et al. (1992), que encontraram degradabilidade ruminal do fubá de milho de 31,10\%, e Ramos et al. (1995), degradabilidade de 33,50\%, utilizando a técnica de saco de náilon móvel. A estimativa média para a digestibilidade da PNDR foi de $60,00 \%$.

Considerando o MDPS, as estimativas médias da proteína degradada no rúmen foram $59,37 \%$ maiores $(45,24 \%)$ que a do glúten de milho (18,38\%) e 29,69\% maiores que a do fubá de milho $(31,81 \%)$. Entretanto, a digestibilidade intestinal foi semelhante à do fubá de milho (66,67\%), o que parece ser contraditório, já que o MDPS apresenta maior fração ligada à parede celular indigestível (Tabela 1). Os resultados médios da proteína degradada no rúmen do farelo de glúten de milho mostraram que esse alimento foi o segundo mais degradadado $(85,21 \%)$.

Ao analisar os grãos moídos, observou-se que as estimativas médias para PDR, PNDR e para a digestibilidade intestinal da PNDR foram semelhantes entre o milheto e o sorgo, sendo de 30,46 e 36,$42 ; 69,80$ e 63,58; e 66,67 e 66,67\%, respectivamente. De acordo com o NRC (1989), a PNDR do sorgo foi de 54,00\%, sendo esse valor $15,07 \%$ menor que o encontrado no presente trabalho. Por outro lado, o grão de amendoim moído resultou em alta degradação ruminal $(81,29 \%)$ e baixa digestibilidade intestinal $(33,33 \%)$. O contrário aconteceu com a polpa cítrica, que teve baixa degradação ruminal $(39,81 \%)$.

As estimativas médias para o farelo de trigo mostraram alta degradação ruminal $(76,61 \%)$ e baixa PNDR $(23,39 \%)$, sendo a digestibilidade intestinal da PNDR de 46,47\%. Esses resultados foram semelhantes aos encontrados por Cabral (1999) $(76,95 ; 23,05$; e $38,18 \%$ ). O NRC (1989) relatou valor de $22,00 \%$ para a PNDR do farelo de trigo, sendo esse valor semelhante ao encontrado nesta pesquisa.

As estimativas médias para a degradabilidade ruminal das camas de frango mostraram que a cama de frango contendo como material absorvente casca de café teve maior proteína degradada no rúmen $(83,20 \%)$, seguida da cama de frango de cepilha de madeira $(52,38 \%)$ e, por último, da cama de frango de capim-elefante $(37,04 \%)$, assim como maior digestibilidade intestinal da PNDR (73,33\%).

Os valores médios da PDR e PNDR e a digestibilidade intestinal da PNDR dos volumosos são apresentados na Tabela 4. Foram encontrados resultados semelhantes para a proteína degradada no rúmen do capim-braquiária $(48,84 \%)$ e do feno de capim-Tifton $(49,07 \%)$, assim como para suas digestibilidades intestinais $(46,67 \%)$. Esses resultados não são consistentes, devido ao fato de o capimbraquiária ter sido coletado no início das águas e o Tifton ter sido previamente submetido à secagem, que, de acordo com os relatos de Van Soest e Sniffen (1984) e McDonald et al. (1988), pode incrementar a quantidade de nitrogênio ligado a componentes da fibra, reduzindo sua disponibilidade ruminal.

Das forragens avaliadas, a maior digestibilidade intestinal da PNDR foi encontrada para a silagem de milho (60,00\%), sendo esse valor 19,58\% maior que o encontrado por Frydrych (1992), de 48,25\%, e $14,28 \%$ menor que o relatado por Rae \& Smithard (1985), de 70,00\%. Avaliando a digestibilidade intestinal da silagem pré-seca de gramíneas, utilizando a técnica do saco de náilon móvel, Frydrych (1992) encontrou resultados semelhantes $(55,43 \%)$ aos obtidos nesta pesquisa $(53,33 \%)$.

As estimativas médias dos parâmetros cinéticos da degradação dos alimentos concentrados avaliados pela técnica dos inibidores in vitro são apresentadas

\begin{tabular}{|c|c|c|c|}
\hline \multicolumn{4}{|c|}{ 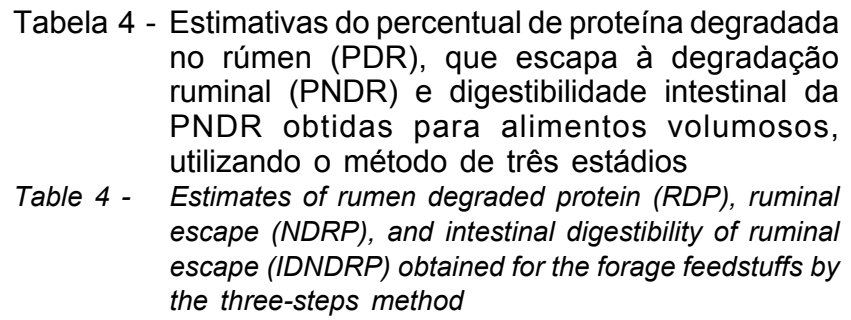 } \\
\hline \multirow{3}{*}{$\begin{array}{l}\text { Alimentos } \\
\text { Feedstuffs }\end{array}$} & $\begin{array}{l}\text { PDR } \\
R D P\end{array}$ & $\begin{array}{l}\text { PNDR } \\
R N D P\end{array}$ & \multirow{3}{*}{ DIPNDR (\%) } \\
\hline & \multicolumn{2}{|c|}{$(\% \mathrm{~PB})$} & \\
\hline & \multicolumn{2}{|c|}{$C P$} & \\
\hline $\begin{array}{l}\text { Capim-braquiária } \\
\text { Signalgrass }\end{array}$ & 48,84 & 51,16 & 46,67 \\
\hline Silagem milho & 28,44 & 71,56 & 60,00 \\
\hline $\begin{array}{l}\text { Silagem pré-seca } \\
\text { de capim-Tifton }\end{array}$ & 57,45 & 42,55 & 53,33 \\
\hline $\begin{array}{l}\text { Tifton haylage } \\
\text { Feno capim-Tifton }\end{array}$ & $\begin{array}{l}49,07 \\
\text { hay }\end{array}$ & 50,93 & 46,67 \\
\hline
\end{tabular}


na Tabela 5. As estimativas da digestibilidade intestinal da PNDR tanto para os concentrados quanto para os volumosos não foram apresentadas, em razão de os resultados não serem consistentes.

De acordo com Bhagavan (1977), o cloranfenicol interfere nas etapas de formação de peptídeos e nos organismos suscetíveis, impedindo o alongamento da cadeia peptídica. Acredita-se, portanto, que o cloranfenicol, além de inibidor da síntese de proteína, participou na sua digestão, inibindo a formação de polipeptídeos.
Observa-se que o método de inibidores in vitro considera em suas estimativas a taxa e extensão da degradação, assim como a taxa de passagem da proteína dos alimentos. Sabe-se que a taxa e extensão da degradação da proteína no rúmen afetam a síntese da proteína microbiana e determinam a quantidade de PNDR que alcança o intestino (Pichard \& Van Soest, 1977; Stern et al., 1994). Proteínas resistentes à degradação ruminal têm sido utilizadas na prática nutricional para aumentar a proteína dietética que chega ao intestino para sua digestão e absorção.

Tabela 5 - Estimativas das taxas de degradação da fração $B(K d)$, fração B, percentual de proteína degradada no rúmen (PDR) e percentual da proteína que escapa à degradação ruminal (PNDR) obtidas para alimentos concentrados e camas de frango, utilizando o método de inibidores in vitro

Table 5 - Estimates of protein degradation rates $(K d)$, fraction $B$, ruminal degradable protein (RDP) and ruminal escape (NDRP) obtained for the concentrates and broiler litter feedstuffs by an inhibitor in vitro method

\begin{tabular}{|c|c|c|c|c|}
\hline $\begin{array}{l}\text { Alimentos } \\
\text { Feedstuffs }\end{array}$ & $\begin{array}{l}\mathrm{Kd}(/ \mathrm{h}) \\
K d\end{array}$ & $\begin{array}{c}\mathrm{B}(\%) \\
\text { Fraction B }\end{array}$ & $\begin{array}{l}\mathrm{PDR}(\%) \\
\quad R D P\end{array}$ & $\begin{array}{l}\text { PNDR }(\%) \\
N D R P\end{array}$ \\
\hline Caseína & 0,265 & 92,50 & 84,15 & 15,85 \\
\hline Casein & & & & \\
\hline $\begin{array}{l}\text { Farelo de soja } \\
\text { Soybean meal }\end{array}$ & 0,155 & 80,30 & 75,58 & 24,42 \\
\hline $\begin{array}{l}\text { Glúten de milho } \\
\text { Corn gluten meal }\end{array}$ & 0,041 & 81,76 & 45,35 & 54,65 \\
\hline $\begin{array}{l}\text { Farelo de glúten de milho } \\
\text { Corn gluten feed }\end{array}$ & 0,522 & 11,43 & 91,25 & 8,75 \\
\hline $\begin{array}{l}\text { Farinha de peixe } \\
\text { Fish meal }\end{array}$ & 0,041 & 94,86 & 45,18 & 54,82 \\
\hline $\begin{array}{l}\text { Farinha de penas } \\
\text { Feather meal }\end{array}$ & 0,038 & 30,13 & 42,74 & 57,26 \\
\hline $\begin{array}{l}\text { Farinha vísceras de aves } \\
\text { Fowl viscera meal }\end{array}$ & 0,073 & 55,27 & 58,93 & 41,07 \\
\hline $\begin{array}{l}\text { Farinha mista vísceras aves-suínos } \\
\text { Fowl-poultry viscera moisture meal }\end{array}$ & 0,077 & 37,10 & 60,67 & 39,33 \\
\hline $\begin{array}{l}\text { Fubá de milho } \\
\text { Corn meal }\end{array}$ & 0,016 & 88,97 & 24,58 & 75,42 \\
\hline $\begin{array}{l}\text { MDPS } \\
\text { Corn, ears and cob }\end{array}$ & 0,181 & 71,70 & 78,41 & 21,59 \\
\hline $\begin{array}{l}\text { Grão de milheto moído } \\
\text { Millet grain, dry ground }\end{array}$ & 0,040 & 92,26 & 44,23 & 55,77 \\
\hline $\begin{array}{l}\text { Grão de sorgo moído } \\
\text { Sorghum grain, dry ground }\end{array}$ & 0,041 & 85,40 & 45,22 & 54,78 \\
\hline $\begin{array}{l}\text { Grão de amendoim moído } \\
\text { Peanut grain, dry ground }\end{array}$ & 0,244 & 68,20 & 83,01 & 16,99 \\
\hline $\begin{array}{l}\text { Polpa cítrica } \\
\text { Citrus dry pulp }\end{array}$ & 0,050 & 46,20 & 50,05 & 49,95 \\
\hline $\begin{array}{l}\text { Farelo de trigo } \\
\text { Wheat bran }\end{array}$ & 0,112 & 65,23 & 69,29 & 30,71 \\
\hline $\begin{array}{l}\text { Cama de frango de casca de café } \\
\text { Broiler litter using coffee rind as adsorvent }\end{array}$ & 0,269 & 36,57 & 84,35 & 15,65 \\
\hline $\begin{array}{l}\text { Cama de frango de capim-elefante } \\
\text { Broiler litter using elephantgrass as adsorvent }\end{array}$ & 0,034 & 39,83 & 40,40 & 59,60 \\
\hline $\begin{array}{l}\text { Cama de frango de cepilha de madeira } \\
\text { Broiler litter using wood rind as adsorvent }\end{array}$ & 0,059 & 45,17 & 54,06 & 45,94 \\
\hline
\end{tabular}


Ao se analisarem as taxas de degradação dos alimentos avaliados, as estimativas mostraram as categorias de proteína, dividindo-as em degradação rápida (farelo de glúten de milho, caseína, grão de amendoim moído, cama de frango de casca de café), intermediária (farelo de soja, MDPS, farelo de trigo, farinha de vísceras de aves e ração vialac) e lenta (fubá de milho, glúten de milho, grão de milheto moído, grão de sorgo moído, polpa cítrica, farinha de peixe, farinha de penas, farinha mista de vísceras de aves e suínos, cama de frango de capimelefante, cama de frango de cepilha de madeira).

A caseína vem sendo utilizada como alimento padrão nos estudos in vitro, devido à sua composição aminoacídica e a sua rápida degradação ruminal (Raab et al., 1983; Broderick, 1987; Neutze et al., 1993). No presente estudo também foi utilizada como alimento padrão durante todas as avaliações. As estimativas médias para a PNDR da caseína $(15,85 \%)$ foram próximas às relatadas pelo NRC (1989) e semelhantes às encontradas por McDonald \& Hall (1954) de 13,00\% com animais canulados no abomaso.

As estimativas médias dos percentuais de proteína não-degradada no rúmen do farelo de soja $(24,42 \%)$ foram semelhantes às encontradas por Stern et al. (1994), 22 a 29,00\%; Cozzi et al. (1995), 25,70\%; Clark et al. (1987), 28,00\%; e England et al. (1997), 28,60\%. O NRC (1989) preconizou $35,00 \%$ para a PNDR do farelo de soja, variando de 14,00 a $82,00 \%$, dependendo do processamento do alimento.

Os resultados obtidos para a proteína não-degradada no rúmen do glúten de milho, 54,65\%, foram próximos daqueles relatados in vivo por Poos-Floyd et al. (1985), 57,90\%, e Clark et al. (1987), 55,00\%. Os resultados encontram-se próximos àqueles publicados pelo NRC (1989), de 22 a 55\%, para esse alimento.
Com relação ao fubá de milho, as estimativas para a PNDR, de $75,42 \%$, foram próximas daquelas do NRC (1989), de 52,00\%, variando de 24,00 a 68,00\%, devido ao processamento.

No que diz respeito aos alimentos de origem animal, notou-se que a farinha de penas obteve a maior PNDR $(57,26 \%)$, seguida da farinha de peixe $(54,82 \%)$, vísceras de aves $(41,07 \%)$ e farinha mista de vísceras de aves e suínos (39,33\%). Resultados semelhantes aos encontrados neste trabalho para a proteína não-degradada no rúmen da farinha de peixe foram relatados por Stern et al. (1983), avaliando a digestibilidade da farinha de peixe in vivo $(59,00$ a 73,00\%), e England et al. (1997) (52,90 e $59,60 \%$ ), ao compararem a técnica in situ com a de inibidores, e próximos aos relatados por Harris et al. (1992), de 60,00\%, avaliada in vivo. O NRC (1989) adotou $60,00 \%$ para a proteína não degradada no rúmen da farinha de peixe.

Ao analisar os grãos moídos, observou-se que o grão de milheto e o sorgo apresentaram resultados próximos para a PNDR, 55,77 e 54,78\%, respectivamente; já a PNDR do amendoim moído foi de $16,99 \%$. Os resultados para PNDR do grão de sorgo moído foram semelhantes aos preconizados pelo NRC (1989), de 49,00\%. As estimativas da PNDR do farelo de trigo foram próximas daquelas citadas pelo NRC (1989).

Com relação aos parâmetros cinéticos da degradação da proteína das camas de frango, observou-se que a menor PNDR foi obtida pela cama de frango de casca de café $(15,65 \%)$ e a maior, pela cama de frango de capim-elefante $(59,60 \%)$.

As estimativas médias dos parâmetros cinéticos da degradação da proteína dos alimentos volumosos são apresentadas na Tabela 6 .

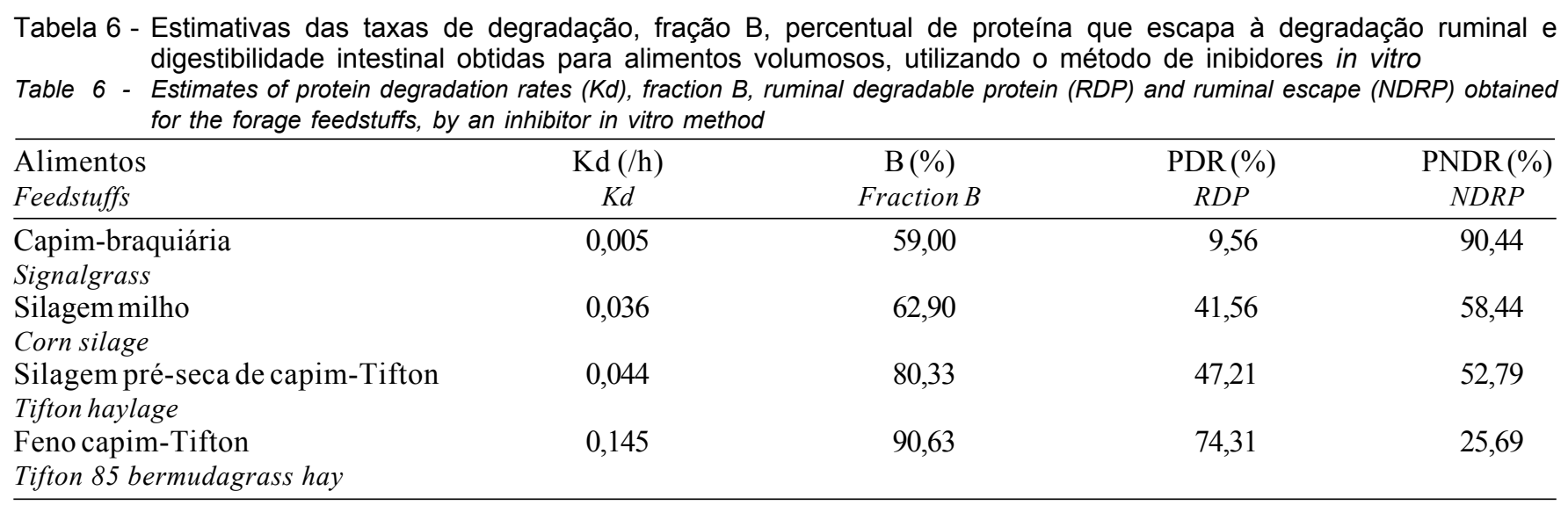




\section{Conclusões}

A digestibilidade intestinal da proteína não-degradada no rúmen dos alimentos não é constante.

O método de três estádios prediz com eficiência a digestibilidade intestinal da proteína não-degradada no rúmen.

\section{Literatura Citada}

AGRICULTURAL AND FOOD RESEARCH COUNCIL AFRC. Nutritive requirements of ruminant animals: protein. Nutrition Abstract Review B, v.62, n. 12, p.787-817, 1992.

AGRICULTURAL RESEARCH COUNCIL - ARC. Report of the protein group of the Agricultural Research Council working party on the nutrient requirements of ruminants. Survey: The Gresham Press, 1984. 45p. (Supplement 1)

ASSOCIATION OF OFFICIAL ANALYTICAL CHEMISTS AOAC. 1990. Official methods of analysis. 15.ed Arlington. v.1. $1117 \mathrm{p}$.

BHAGAVAN, N.V. Bioquímica. 1.ed. Rio de Janeiro: Interamericana, $1977.817 \mathrm{p}$.

BRODERICK, G.A. Determination of protein degradation rates using a ruminal in vitro system containing inhibitors of microbial nitrogen metabolism. British Journal Nutrition, v.58, n.5, p.463- 475, 1987.

CABRAL, L.S. Cinética ruminal das frações de carboidratos e proteínas e digestão intestinal da proteína de alimentos por intermédio de técnicas in vitro. Viçosa, MG: Universidade Federal de Viçosa, 1999. 80p. Dissertação(Mestrado em Zootecnia) - Universidade Federal de Viçosa, 1999.

CALSAMIGLIA, S.; STERN, M.D. A three-step in vitro procedure for estimating intestinal digestion of protein in ruminants. Journal of Animal Science, v.73, n.5, p.1459-1465, 1995.

CASTILlO, A.M.A. Avaliação da degradabilidade ruminal e da digestibilidade intestinal de vários alimentos, utilizando-se a técnica do saco de náilon móvel. Viçosa, MG: Universidade Federal de Viçosa, 1992. 108p. Dissertação (Mestrado em Zootecnia) - Universidade Federal de Viçosa, 1992.

CLARK, J.H.; MURPHY, M.R.; CROOKER, B.A. Supplying the protein needs of dairy cattle from by-products feeds. Journal of Dairy Science, v.70, n.5, p.1092-1109, 1987.

COZZI, G.; ANDRIOGHETTO, I.; BERZAGHI, P. et al. In situ ruminal disappearance of essential amino acids in protein feedstuffs. Journal of Dairy Science, v.78, n.1, p.161-171, 1995.

DE BOER, G.; MURPHY, J.J.; KENNELLY, J.J. Mobile nylon bag for estimating intestinal availability of rumen undegradable protein. Journal of Dairy Science, v.70, n.5, p.977-982, 1987.

ENGLAND, M.L.; BRODERICK, G.A.; SHAVER, R.D. et al. Comparison of in situ and in vitro techniques for measuring ruminal degradation of animal by-product proteins. Journal of Dairy Science, v.80, n.11, p.2925-2931, 1997.

FRYDRYCH, Z. Intestinal digestibility of rumen undegraded protein of various feeds as estimated by the mobile bag technique. Animal Feed Science Technology, v.37, n.1, p.161-172, 1992.
HARRIS Jr., B.; DORMINEY, D.E.; SMITH, W.A. et al. Effects of feather meal at two protein concentrations and yeast culture on production parameters in lactating dairy cows. Journal of Dairy Science, v.75, n.12, p.3524-3530, 1992.

HVELPLUND, T.; WEISBJERG, M.R.; ANDERSON, L.S. Estimation of the true digestibility of rumen undegraded dietary protein in the small intestine of ruminants by the mobile bag technique. Acta Agriculture Scandinavia, v.42, n.1, p.34-44, 1992.

KENDALL, E.M.; INGALLS, J.R.; BOILA, J.R. Variability in the rumen degradability and postruminal digestion of the dry matter, nitrogen and amino acids of canola meal. Canadian Journal of Animal Science, v.71, n.5, p.739-748, 1991.

KUNG, Jr., L.; TUNG, R.S.; CARMEAN, B.R. Rumen fermentation and nutrient digestion in cattle fed diets varying in forage and energy source. Animal Feed Science and Technology, v.39, n.1, p.1-12, 1992.

LICITRA, G.; HERNANDEZ, T.M.; VAN SOEST, P.J. Standardization of procedures for nitrogen fractionation of ruminant feeds. Animal Feed Science and Technology, v.57, n.4, p.347-358, 1996.

LONDOÑO HERNÁNDEZ, F.I.; BONECARRERE, S.L.M.; VIEIRA, R.A. et al. Desaparecimento ruminal e digestibilidade intestinal e total da matéria seca e proteína bruta de alguns suplementos concentrados. Revista Brasileira de Zootecnia, v.27, n.4, p.777-782, 1998.

LONDOÑO HERNÁNDEZ, F.I.; VALADARES FILHO, S.C.; MANCIO, A.B. et al. Validação do método de inibidores in vitro para estimação da degradação da proteína de alimentos. In: REUNIÃO ANUAL DA SOCIEDADE BRASILEIRA DE ZOOTECNIA, 37., 2000, Viçosa. Anais...Viçosa: Sociedade Brasileira de Zootecnia, 2000, p.498.

MAIGA, H.A.; SCHINGOETHE, J.D.; HENSON, J.E. Ruminal degradation, amino acid composition, and intestinal digestibility of the residual components of five protein supplements. Journal of Dairy Science, v.79, n.9, p.16471653, 1996.

MASOERO, F.; FIORENTINI, L.; ROSSI, F. et al. Determination of nitrogen intestinal digestibility in ruminants. Animal Feed Science and Technology, v.48, n.3,4, p.237-264, 1994.

McCARTHY, R.D.; KLUSMEYER, T.H.; VICINI, J.L. et al. Effects of source of protein and carbohydrate on ruminal fermentation and passage of nutrients to the small intestine of lactating cows. Journal of Dairy Science, v.72, n.8, p.2002-2016, 1989.

McDONALD, P.; EDWARDS, R.A.; GREENHALGH, J.F.D. Animal nutrition. 4.ed. New York: Longman, 1988. 543p.

McDONALD, I.W., HALL, R.J. The conversion of casein into microbial proteins in the rumen. Biochemical Journal, v.67, n.6, p.400-405, 1954.

MERCHEN, N.R.; ELIZALDE, J.C.; DRACKLEY, J.K. Current perspective on assessing site of digestion in ruminants. Journal of Animal Science, v.75, n.8, p.2223-2234, 1997.

NATIONAL RESEARCH COUNCIL - NRC. Nutrient requirements of dairy cattle. 7.rev.ed. Washington, D.C.: National Academic Press, 2001. 381p.

NATIONAL RESEARCH COUNCIL - NRC. Nutrient requirements of dairy cattle. 6.ed. Washington, D.C.: National Academy Press, 1988.

NATIONAL RESEARCH COUNCIL - NRC. Nutrient requirements of dairy cattle. 6.rev.ed. (update 1989) National Academy Press, Washington, DC. 157p. 
NEUTZE, S.A.; SMITH, R.L.; FORBES, W.A. Application of an inhibitor in vitro method for estimating rumen degradation of feed protein. Animal Feed Science and Technology, v.40, n.4, p.251-265, 1993.

PICHARD, G.; VAN SOEST, P.J. Protein solubility of ruminant feeds. Proceedings of Cornell nutrition conference, Cornell, Ithaca, 1977. p.11.

POOS-FLOYD, M.; KLOPFENSTEIN, T.; BRITTON, R.A. Evaluation of laboratory techniques for predicting ruminal protein degradation. Journal of Dairy Science, v.68, n.4, p.829-839, 1985.

RAAB, L.; CAFANTARIS, B.; JILG, T. et al. Rumen protein degradation and biosynthesis. 1. A new method for determination of protein degradation in rumen fluid in vitro. British Journal of Nutrition, v.50, n.6, p.569-582, 1983.

RAMOS, S.M.; VALADARES FILHO, S.C.; COELHO DA SILVA, J.F. et al. Digestibilidade intestinal dos alimentos com a técnica de saco de náilon móvel em novilhos cecocolectomizados. In: REUNIÃO ANUAL DA SOCIEDADE BRASILEIRA DE ZOOTECNIA, 32., 1995, Brasília. Anais...Brasília: Sociedade Brasileira de Zootecnia, 1995. p. 247-249.

RAE, R.C.; SMITHARD, R.R. Estimation of true nitrogen digestibility in cattle by a modified nylon bag technique. Proceeding of Nutrition Society, v.44, n.1, p.116A, 1985.

STERN, M.D.; ORTEGA, M.E.; SATTER, L.D. Retention time in rumen and degradation of protein supplements fed to lactating dairy cattle. Journal Dairy Science, v.66, n.4, p.1264-1275, 1983.

STERN, M.D.; CALSAMIGLIA, S.; ENDRES, M.I. Dynamics of ruminal nitrogen metabolism and their impact on intestinal protein supply. In: CORNELL NUTRITION CONFERENCE FOR FEED MANUFACTURES, 1994, Ithaca. Proceedings... Ithaca: Cornell University, 1994. p.105-116.

STERN, M.D.; BACH, A.; CALSAMIGLIA, S. Alternative techniques for measuring nutrient digestion in ruminants. Journal of Animal Science, v.75, n.8, p.2256-2276, 1997.
SNIFFEN, C.J.; O'CONNOR, J.D.; VAN SOEST, P.J. et al. A net carbohydrate and protein system for evaluating cattle diets: II Carbohydrate and protein availability. Journal of Animal Science, v.70, n.11, p.3562-3577, 1992.

TITGEMEYER, E.C.; MERCHEN, N.R.; BERGER, L.L. Evaluation of soybean meal, corn gluten meal, blood meal and fish meal as sources of nitrogen and amino acids disappearing from the small intestine of steers. Journal of Animal Science, v.67, n.3, p.262-275, 1989.

VALADARES FILHO, S.C. Eficiência de síntese de proteína microbiana, degradação ruminal e digestibilidade intestinal da proteína bruta, em bovinos. In: SIMPOSIO INTERNACIONAL SOBRE EXIGÊNCIAS NUTRICIONAIS DE RUMINANTES, 1995, Viçosa, MG. Anais... Viçosa, 1995, p.355-388.

Van SOEST, P.J.; SNIFFEN, C.J. Nitrogen fractions in NDF and ADF. Distiller's Feed Conference, v.39, p.72-82, 1984.

Van STRAALEN, W.M.; TAMMINGA, S. Feedstuffs evaluation. In: WISEMAN, J.; COLE, D.J.A. (Eds.) London: Butterworths, 1990.105p.

ZERBINI, E.; POLAN, C. Protein sources evaluated for ruminating holstein calves. Journal of Dairy Science, v.68, n.6, p.1416-1424, 1985. 